\title{
DIASPORA. SENIIDOS SOCIAIS E MOBILIDADES HAITIANAS
}

\author{
Joseph Handerson* \\ Universidade Federal do Amapá - Brasil
}

Resumo: O termo "diáspora" foi objeto de inúmeras pesquisas, descrevendo as experiências das diásporas judaica, grega e armênia. A partir da década de 1990, o seu uso generalizou-se, tornando-se popular na linguagem cotidiana. Neste texto, procura-se privilegiar os conteúdos etnográficos do termo entre os haitianos, explorando os sentidos sociais da categoria de diaspora (e o campo semântico que ele delineia). Mostra-se como essa categoria é central para compreender os sentidos sociais da mobilidade no espaço (trans)nacional haitiano, qualificando pessoas, objetos, casas, dinheiro e ações.

Palavras-chave: diaspora, Haiti, mobilidade haitiana, transnacional.

Abstract: The term diaspora has been the subject of numerous studies describing the experiences Jewish, Greek and Armenian diasporas. From the 1990s, its use became widespread, making it common in everyday language. In this paper, we seek to focus the ethnographic content of the word among Haitians, exploring the social meanings of the category of diaspora (and the semantic field constitutes). It is shown how this is central category for understanding the social meanings of mobility in the Haitian (trans)national space, describing people, objects, houses, money and practices.

Keywords: diaspora, Haiti, Haitian mobility, transnational.

Desde a década de 1990, a diaspora haitiana é objeto de inúmeras pesquisas. ${ }^{1}$ Nessa mesma época, o seu uso se generalizou no espaço (trans)nacional

\footnotetext{
* Contato: handersonj_82@yahoo.es.

1 Este artigo é uma versão resumida do argumento desenvolvido no quinto capítulo da minha tese de doutorado defendida no Programa de Pós-Graduação em Antropologia Social/Museu Nacional-UFRJ. Agradeço ao Prof. Dr. Federico Neiburg - meu orientador da tese - pela leitura crítica e comentários em relação ao texto. A primeira versão deste texto foi apresentada nos seminários "Modes de gouvernement et pratiques économiques ordinaires: approche comparative” (2013-2014) na École Normale Supérieure (ENS) em Paris, coordenado por Dr. Benoît de l’Éstoile, “Diasporas, migrations
} 
haitiano, particularmente no discurso político. A maior parte da literatura que trata da migração haitiana acentua a configuração da diaspora nos Estados Unidos, França, Canadá e Caribe (Audebert, 2012; Basch; Glick-Schiller; Szanton-Blanc, 1994, entre outros). Segundo os dados oficiais do Ministério dos Haitianos Residentes no Exterior (MHAVE, a sigla em francês), aproximadamente entre 4 a 5 milhões de haitianos estão espalhados pelo mundo, a maior parte nos países mencionados. ${ }^{2}$ Isso representa a metade dos habitantes do Haiti, estimados em 10.413.211 em 2013 pelo Institut Haïtien de Statistique et d'Informatique (IHSI). Dentre aqueles no exterior, 300 mil visitam anualmente o Haiti, particularmente nos períodos festivos e de férias.

Dentre esses, cerca de 7 mil passaram pela Tríplice Fronteira Brasil, Colômbia e Peru entre 2010 e 2013 e, atualmente, seriam entre 35 mil a 40 mil no Brasil, ${ }^{3}$ em uma população migrante registrada e estimada em 1,5 milhão no universo da população local de 202 milhões; 15 mil a 17 mil no Suriname, dos quais 9 mil seriam regularizados, em uma população total de $430 \mathrm{mil}$ habitantes (Granger, 2007, p. 291); e 33.500 na Guiana Francesa, sendo uma das maiores populações migrantes no departamento ultramarino, de acordo com os dados do Institut National de la Statistique et des Études Économiques (INSEE). Mas, segundo o cônsul haitiano no local, eles seriam estimados entre 40 mil a 50 mil, entre regularizados e indocumentados num universo de uma população legal, em 2011, estimada em 237.550 habitantes (Catherine; Treyen, 2014).

Interessa mostrar, tanto fora como dentro do Haiti, que o termo diaspora é uma categoria organizadora do mundo, pois designa pessoas, qualifica

et religions” (2013-2014) na Universidade de Toulouse 2 - Le Mirail, coordenado por Chantal BordesBenayoun e, em fevereiro de 2014, no laboratório de Migrinter da Universidade de Poitiers, dirigido por Cédric Audebert. Agradeço aos coordenadores e aos participantes pelos comentários. Os estudos foram financiados pela Coordenação de Aperfeiçoamento de Pessoal de Nível Superior (Capes) e Comitê Francês de Avaliação da Cooperação Universitária com o Brasil (Cofecub).

2 De acordo com os dados do Congresso Mundial Haitiano (CMH) do ano de 2005, em Nova York (incluindo Nova Jersey) são estimados em 1 milhão; em Miami, 750 mil; em Boston, Chicago e Los Angeles, 150 mil; no Canadá, 120 mil; na França, 100 mil, incluindo os departamentos ultramarinos; na República Dominicana, 750 mil; em Cuba, 400 mil; e nos demais países da América Latina, 75 mil, além daqueles instalados na África e na Ásia (Congrès Mondial Haïtien, 2005, p. 16).

3 Os dados devem ser problematizados porque é complexo afirmar números bem definidos, visto ser quase impossível mensurar um mundo em movimento. Além de, possivelmente, nem todos os imigrantes terem passado pela Polícia Federal brasileira ou enviado os seus dados para o Conselho Nacional de Imigração (CNIg), e sabemos das dificuldades inerentes às fontes convencionais.

Horizontes Antropológicos, Porto Alegre, ano 21, n. 43, p. 51-78, jan./jun. 2015 
objetos, dinheiro, casas e ações. O termo diaspora é utilizado para designar os compatriotas residentes no exterior, mas que voltam temporariamente ao Haiti e logo retornam para o exterior: diaspora ki jan ou ye? (diaspora, como você vai?). ${ }^{4} \mathrm{O}$ campo semântico e polissêmico do termo está articulado por três verbos associados a diaspora: residir no exterior, voltar ao Haiti e retornar ao exterior. ${ }^{5}$

As músicas haitianas produzidas no exterior são chamadas músicas de diaspora. As roupas enviadas são denominadas rad diaspora (roupa diaspora); o dólar americano e o euro, lajan diaspora (moedas diaspora); as casas construídas no Haiti por compatriotas residentes no exterior, combinando objetos (eletrônicos e eletrodomésticos, etc.), materiais de construção (cerâmicas, portas, janelas, luzes, etc.) do exterior com os do país, são denominadas kay diaspora (casas diaspora). A categoria diaspora também serve para qualificar ações, como nas expressões: w’ap fè bagay diaspora (está fazendo coisa de diaspora), ou aji tankou diaspora (você age como diaspora).

Os novos fluxos de mobilidade haitiana na escala supranacional permitem uma nova abordagem da polissemia do termo diaspora. A partir do meu trabalho de campo, pergunto: será que o uso generalizado do termo diaspora entre os haitianos pode trazer novas pistas, inspirando novas concepções e maior compreensão mesmo nas suas condições de uso e ambiguidades? O sentido prático mais amplo do termo diaspora não seria um desafio epistemológico e analítico?

$\mathrm{Na}$ tentativa de ponderar tais questionamentos, opto pelo modelo etnográfico para sustentar o núcleo da minha argumentação, problematizando a maneira pela qual William Safran (1991), Robin Cohen (1997), entre outros, têm discutido a categoria de diáspora por meio de um "modelo centrado", segundo James Clifford (1994, 1999), utilizando alguns critérios classificatórios

4 As expressões e frases mais curtas enunciadas pelos sujeitos da pesquisa são conservadas na língua original créole, além das traduções em português entre parênteses ou vice-versa.

5 Utilizarei a palavra diaspora em itálico e sem acento para destacar o seu uso em créole entre os haitianos, língua oficial do Haiti junto com o francês. A palavra é escrita também em créole com “y”, dyaspora. Também utilizarei o termo com acento e sem itálico (diáspora) para destacar o seu sentido analítico. Uso o termo diaspora sem o artigo "a”, ou seja, a diaspora, para abranger o seu uso além da referência à pessoa, enquanto sujeito, mas também como adjetivo, qualificando pessoas, objetos, casas, dinheiro e ações. A palavra é utilizada no singular e não no plural, “diaspora” em vez de "diasporas” visto que no universo haitiano, particularmente na língua créole, ela não possui "s” no final. 
para definir o conceito de diáspora. Dispenso a história lexicológica ${ }^{6}$ e conceitual da palavra "diáspora"7 e o debate acadêmico sobre o sentido original desta categoria. ${ }^{8}$ Privilegio uma abordagem pragmática, ou seja, discutindo os significados e os usos práticos do termo diaspora partindo da realidade e dos conteúdos etnográficos da palavra entre haitianos e estrangeiros, situados em diferentes contextos de interação, explorando os sentidos êmicos da categoria.

$\mathrm{O}$ artigo faz refletir sobre o modo pelo qual o termo diaspora dá forma, sentido e constitui o mundo social haitiano (especialmente no espaço nacional haitiano). A pesquisa etnográfica considera a experiência de mobilidade ao longo de circuitos que atravessaram o Brasil e, em muitos casos, incluiu, também, o Suriname e a Guiana Francesa, destino de vários dos sujeitos da pesquisa. ${ }^{9}$ Ao mesmo tempo, mostra o termo diaspora associado à mobilidade transnacional como constitutiva da trajetória de vida das pessoas e dos horizontes de possibilidades delas.

\section{Sentidos analíticos e políticos do termo diaspora}

De acordo com Nina Glick-Schiller (2011), o termo diaspora se popularizou em 1980 entre haitianos nos Estados Unidos, particularmente em Nova York, como parte do movimento popular contra a ditadura duvalierista. Em 1985, das 96 lideranças haitianas entrevistadas na área metropolitana de Nova York (Glick-Schiller, 2011, p. xxvi, tradução minha), "somente aquelas ligadas diretamente com os padres católicos ou provindas dos meios de comunicação haitianos tinham ouvido falar do termo diaspora". Muitos nunca o tinham escutado ou ouvido falar nele. Nesse primeiro momento, o termo foi mobilizado pelos padres católicos como recurso político para reivindicar os direitos nos Estados Unidos e denunciar a ditadura no Haiti.

Segundo Glick-Schiller, a constituição da "diáspora haitiana” e o uso do termo "comunidade haitiana” foram fundamentais para a articulação

\footnotetext{
Para uma abordagem historiográfica da palavra “diáspora”, ver os trabalhos de Dufoix (2003, 2011). Ver os trabalhos de Safran (1991), Clifford (1994, 1999), Cohen (1997), entre outros.

Sugiro os trabalhos de Schnapper (2001) e Bordes-Benayoun (2012).

9 O trabalho de campo se concentrou, numa primeira etapa, na Tríplice Fronteira e em Manaus, entre janeiro e março de 2012; numa segunda, no Suriname (Paramaribo) e na Guiana Francesa (Cayenne), de março a maio de 2013; e, numa terceira, no Haiti (Fonds-des-Nègres e Pemerle), em julho desse mesmo ano.
} 
de projetos comunitários de jornais, televisões e associações dos haitianos nos Estados Unidos. Foi uma forma encontrada para descrever suas experiências e constituir uma agenda política. No espaço nacional haitiano, o uso do termo iniciou a partir do retorno, em 1986, dos compatriotas exilados durante a ditadura dos Duvaliers. Em 1990, tinha-se generalizado o uso do termo diaspo$r a$, tornando-se comum entre os haitianos no Haiti e fora dele. Nesse mesmo período, ele se integrou ao vocabulário de uma das línguas oficiais do país caribenho, o créole, escrito com “y”, dyaspora.

Julgo pertinente a abordagem de James Clifford (1994, 1999), pela sua proposta das traveling cultures, na medida em que ele analisa criticamente o "ideal típico" do modelo fechado de "diáspora" com critérios bem definidos, formulados por William Safran (1991). A crítica de Clifford é dirigida também à visão descentrada que se interessa mais pelas fronteiras da diáspora do que por seu coração, para compreender a que a diáspora se opõe, isto é, de acordo com o referido autor, ao Estado-nação: Israel é o primeiro exemplo.

É relevante também a abordagem de Stéphane Dufoix (2003, 2011), pela análise da evolução do uso do termo. Foram vários os trabalhos na tentativa de definir diaspora, notadamente dos anglo-saxões William Safran (1991), ${ }^{10}$ Robin Cohen (1997) e os franceses Dominique Schnapper (2001) e Chantal Bordes-Benayoun (2012), entre outros. Os princípios teóricos e empíricos que essa literatura traz são pertinentes inclusive para problematizar o modo como o termo organiza e expressa uma experiência individual e coletiva no mundo social haitiano.

No entanto, neste trabalho, analiso o termo diaspora sem a preocupação de defini-lo, e muito menos discutir se há uma diaspora haitiana ou não, num plano a priori ou de acordo com alguns dos critérios estabelecidos pelos estudiosos sobre essa questão. Do ponto de vista etnográfico, na categoria de diaspora há uma junção de sentidos políticos, econômicos, morais e históricos,

${ }^{10}$ Utilizo a definição do termo “diáspora” de William Safran, visto que foi uma das primeiras tentativas de construir um modelo conceitual fechado com vários critérios. O seu artigo foi publicado na revista norte-americana Diaspora, editada por Kachig Tölölyan. Safran (1991) define “diásporas” como comunidades de minorias expatriadas: a) que se encontram dispersas a partir de um centro de origem para, pelo menos, dois espaços “periféricos”; b) que mantêm uma “memória” mítica da "terra de origem” (homeland); c) que sentem que não são - e, talvez, não podem ser - totalmente aceitos nos países de acolhida; d) que veem a sua terra natal como um lugar de retorno no momento oportuno; e) que são engajados na manutenção ou reconstrução da "terra de origem” (homeland); e f) para os quais, a consciência e a solidariedade do grupo são fortemente definidas pelos laços contínuos com a "terra de origem” (homeland).

Horizontes Antropológicos, Porto Alegre, ano 21, n. 43, p. 51-78, jan./jun. 2015 
relativos à própria "pessoa”. Por exemplo, ela serve como adjetivo para qualificar pessoas: “diaspora, como você vai?”, “diaspora chegou”. A abordagem etnográfica aqui apresentada é, nesse sentido, diferente das discussões travadas na literatura sobre diápora(s).

Os sentidos políticos e históricos estão articulados à comunidade haitiana fora do país, na mesma acepção utilizada no contexto norte-americano. O governo haitiano, quando menciona o termo diaspora, é para referir-se aos haitianos com residência permanente fora do país. A sua formulação e o seu significado político constituíram-se quando o ex-presidente Jean-Bertrand Aristide, no seu discurso de posse em 1991, recebeu diaspora no Palácio Nacional em Port-au-Prince e os cumprimentou como os haitianos do décimo departamento:11 “diaspora”, no sentido simbólico. No entanto, não existia ainda, de fato, um décimo departamento do ponto de vista geográfico e jurídico.

Embora, na época, o Haiti possuísse legalmente apenas nove distritos administrativos, chamados departamentos, no ano de 2003, o governo criou um décimo departamento geográfico, chamado de Nippes, na região sul do país. Este sentido político se justificou essencialmente no reconhecimento da existência de uma ordem política e econômica dentro da qual o Haiti se insere enquanto país de emigração e de mobilidade. No discurso de posse de Aristide, foi evidenciado esse reconhecimento através do agradecimento à participação ativa dos haitianos da diaspora na vida social e política do país, sobretudo porque aqueles residentes, particularmente nos Estados Unidos, apoiaram a sua candidatura, financiando e contribuindo na multiplicação dos organismos associados à sua campanha eleitoral.

Esse sentido de instrumentalização política continua até hoje, com conteúdo diferente nas políticas e redes internacionais mobilizadas pelo atual presidente Joseph Michel Martelly, considerando as pessoas de ascendência haitiana que residem no exterior como haitianos. Contudo, juridicamente, não é bem assim. A Constituição de 1987 não permite a dupla nacionalidade. Segundo a legislação, quem opta por outra nacionalidade automaticamente rejeita a cidadania haitiana e perde alguns direitos políticos e sociais (Achille, 2007).

No Haiti, do ponto de vista da lei, a pessoa diaspora naturalizada não poderia participar da vida política plena do país: votar, candidatar-se

11 A expressão “décimo departamento” foi criada em 1990 pelo geógrafo haitiano Georges Anglade.

Horizontes Antropológicos, Porto Alegre, ano 21, n. 43, p. 51-78, jan./jun. 2015 
a determinados cargos políticos, ser nomeado ministro, etc. Segundo a Constituição do dia 10 de março de 1987, o seu artigo 11 diz o seguinte: "Possui a nacionalidade haitiana de origem, todo indivíduo nascido de um pai haitiano ou de uma mãe haitiana, sendo eles também nascidos haitianos e não tenham renunciado à sua nacionalidade por ocasião do nascimento.” (Achille, 2007, p. 21, tradução minha). Mais adiante, a referida Constituição estipula: "Que a nacionalidade haitiana se perde pela naturalização adquirida num país estrangeiro (artigo 13.1), e repete, que a nacionalidade de origem se perde pela renúncia (artigos 91.1; 96.1; 135.1; 157.1; 200-5.1).” (Achille, 2007, p. 21, tradução minha). Nesse sentido, a "perda" da nacionalidade haitiana se exprime através de dois termos diferentes, mas expressando a mesma ideia, utilizados como sinônimos. Eles são destacados e sublinhados na própria Constituição, "naturalização" e "renúncia”.

Mas essa ideia deve ser nuançada, porque pode haver diferenças entre o que diz a lei e as práticas reais, notadamente no Haiti. A partir de junho de 2012, o atual presidente Michel Martelly promulgou uma emenda constitucional, concedendo o direito à dupla nacionalidade, podendo o cidadão haitiano ter mais de um passaporte, além de votar e concorrer a diversas funções eleitorais. Logo após essa promulgação, vários compatriotas no exterior se pronunciaram, enfatizando a decisão como um momento histórico para o país e aqueles na diaspora, há muitos anos querendo participar na vida política da nação.

Importa salientar que, antes da elaboração da emenda, já existiam dois ministérios para tratar de assuntos relacionados à diaspora haitiana: o Ministério dos Assuntos Estrangeiros e o Ministério dos Haitianos Residentes no Exterior (MHAVE). ${ }^{12}$ Sob a responsabilidade deste último está a maior parte dos serviços de emigração, como celebrar a "Jornada Internacional da Diaspora" realizada no mês de abril de cada ano, originada em 2011, a partir de um decreto do ex-presidente René Préval. O tema da jornada, realizada de 16 a 22 de abril de 2012, foi "o Haiti necessita de sua diaspora”, dando ênfase à importância da diaspora na realidade socioeconômica, educacional

${ }^{12}$ Cf. http://www.mhave.gouv.ht/. A ideia da criação de um ministério que cuide das questões dos haitianos residentes no exterior surgiu na década de 1970. Ela foi sendo gestada até a criação da Secretaria do Décimo Departamento (SEDID), vinculada à Presidência da República (1991), ganhando status de Ministério dos Haitianos Residentes no Exterior em 1994.

Horizontes Antropológicos, Porto Alegre, ano 21, n. 43, p. 51-78, jan./jun. 2015 
e política do país. Na apresentação da página do ministério na internet, há a frase: "Os compatriotas do Exterior devem ser vistos como atores e não como observadores nas questões de seu país”. ${ }^{13}$

A instrumentalização política da diaspora haitiana apresenta certa ambiguidade. Quando os haitianos da diaspora são convidados ou acionados pelo governo a fim de contribuir para o desenvolvimento do seu país, geralmente são considerados atores mobilizadores de recursos econômicos. Por mais que a emenda constitucional permita uma nova reflexão sobre o lugar da diaspora na esfera política do país, as práticas reais continuam sendo antagônicas. A inserção das pessoas diaspora como agentes políticos, notadamente nas eleições, não é de fato incentivada. É nesse sentido que uma das recomendações feitas pelos haitianos presentes no Forum de la Diaspora Haïtienne, realizado nos dias 21, 22 e 23 de março de 2010, nos estabelecimentos da Organização dos Estados Americanos (OEA) em Washington foi: "Utilizar as competências da diaspora para dar prosseguimento no processo de reforma da Constituição e, notadamente, das disposições relativas à obtenção da dupla nacionalidade aos membros da diaspora." (Consolidated recommendations, 2010, p. 12, tradução minha).

Para além do plano legal, há uma dimensão do pertencimento que envolve sentimentos e não só as leis. Através da criação simbólica da ideia do décimo departamento haitiano em 1990, muito antes da existência legal do décimo departamento geográfico em 2003, o governo fazia (e continua fazendo) acreditar ser possível aos haitianos participarem da vida política do seu país sem estarem fisicamente nele. É o que os autores da abordagem do transnacionalismo (Basch; Glick-Schiller; Szanton-Blanc, 1994) chamam de "nações sem fronteiras", as nations unbound, uma espécie de "nacionalismo à longa distância” (Glick-Schiller; Fouron, 2001), constituído através da noção de pertencimento que os migrantes possuem, independentemente dos seus lugares de residência no exterior. ${ }^{14}$

${ }^{13}$ Cf. http://www.mhave.gouv.ht/.

14 Segundo a definição de Glick-Schiller (2005, p. 570-571, tradução minha): "Nacionalismo à longa distância está intimamente ligado à noção clássica do nacionalismo e do Estado-nação. Como em outras formas de nacionalismo, os nacionalistas à longa distância acreditam que há uma nação que consiste de pessoas que compartilham uma história comum, identidade e território. Nacionalismo à longa distância difere de outras formas de nacionalismo em termos da natureza do relacionamento entre os membros da nação e do território nacional. As fronteiras nacionais não são pensadas para delimitar a adesão ao

Horizontes Antropológicos, Porto Alegre, ano 21, n. 43, p. 51-78, jan./jun. 2015 
Além de ser uma experiência social, diaspora é uma questão também política. Essa configuração do sentimento de pertencimento leva-os a tomar posição política e se pronunciar em relação aos modos da governamentalidade do seu país, no sentido foucaultiano. Tal ideia está associada ao fato de os sujeitos intervirem na vida política do seu país - além da social e da econômica - mesmo estando fora do território nacional. Tal dimensão coloca esses sujeitos numa outra escala, visto o seu "nacionalismo à longa distância” não ser um "simples" pertencimento ou de uma consciência diaspórica, tal como foi analisado por Paul Gilroy (1993) em The Black Atlantic: modernity and double consciousness. Diante disso, a experiência haitiana sugere uma nova percepção e relacionamento do Estado-nação com o território, constituindo um sentimento de extraterritorialidade, apesar de suas ambiguidades.

\section{Diaspora, como você vai?}

O termo diaspora serve como adjetivo para qualificar pessoas, além de designar a comunidade haitiana transnacional. É comum os haitianos no Haiti usarem a palavra diaspora para chamar outro compatriota que parte, reside aletranje (no exterior), envia remessas, etc.: diaspora ki jan ou ye? (diaspora, como você vai?); sa k'ap fèt diaspora? (o que tem feito, diaspora?); mwen se diaspora (sou diaspora). Essas expressões caracterizam o termo diaspora como categoria de autodesignação e de alteridade, permitindo diferenciar os que vivem aletranje em relação àqueles que ficam no Haiti. No Brasil, no Suriname, na Guiana Francesa e no Haiti de modo particular (também nos Estados Unidos, França, Canadá e em outros países do Caribe), o termo é utilizado para designar os compatriotas que residem aletranje, mas voltam temporariamente ao Haiti e logo retornam aletranje. As dimensões de tempo e espaço são cruciais para a compreensão dos sentidos sociais do termo diaspora. Além de a pessoa precisar residir num espaço internacional para

país. Os membros da nação podem viver em qualquer lugar ao redor do planeta e até mesmo possuir a cidadania em outros Estados. Isso não significa, na visão dos nacionalistas à longa distância, revogar a relação entre os membros da nação e sua pátria nacional. Os nacionalistas à longa distância procuram manter a lealdade para com a terra de origem e, com base neste anexo, tomar quaisquer medidas que a pátria exige.”

Horizontes Antropológicos, Porto Alegre, ano 21, n. 43, p. 51-78, jan./jun. 2015 
ser considerado diaspora, também deve permanecer por um longo período de tempo ali antes de voltar ao Haiti.

A volta deve mostrar o sucesso pessoal e coletivo da diaspora. Não há diaspora sem a volta temporária. Do ponto de vista etnográfico, não é um retorno, é uma nova chegada. Essa última ideia deve ser explicada nas próprias categorias e expressões nativas. Os haitianos não usam a palavra créole tounen, significando retorno, para descrever a experiência da nova chegada da pessoa diaspora, mas sim a expressão diaspora rive: diaspora chegou ou diaspora vini: diaspora veio, do ponto de vista dos que ficaram. Os viajantes utilizam a expressão diaspora pral vizite Ayiti (diaspora vai visitar o Haiti) ou diaspora ap desann Ayiti (literalmente: diaspora vai descer para o Haiti).

A nova chegada ao Haiti caracteriza-se como uma visita viabilizada por meio dos laços afetivos, familiares, de amizade ou laços com as casas construídas no Haiti. As construções de casas e os laços com o Haiti também contribuem para a pessoa diaspora não se isolar do próprio país. Do ponto de vista dos que ficam, a volta da pessoa diaspora constitui um ato e uma demonstração de fidelidade ao Haiti e aos familiares. Glick-Schiller e Fouron (2001) se referem a esses laços familiares e sociais como "laços de sangue com o Haiti".

Nesse sentido, as palavras de Michel Bruneau (2004) são cruciais para entender a dimensão familiar da diaspora. Segundo o referido autor:

Não há diáspora sem a célula familiar, por meio da qual se transmite a consciência identitária. Tampouco não há diáspora sem laços de parentesco, real ou imaginário, ultrapassando as fronteiras estatais. Estes laços familiares permitem ao exilado não sucumbir ao isolamento destrutivo e não ser totalmente absorvido ou assimilado pela sociedade de acolhida. As redes de diáspora se apoiam, primeiramente sobre as redes familiares. (Bruneau, 2004, p. 45, tradução minha).

Há uma relação indissociável entre família e diaspora. Mais do que enviar dinheiro e objeto, muitos daqueles no Haiti esperam do viajante fil (solicitar visto permanente para familiares próximos, pais, filhos e irmãos), ${ }^{15}$ "mandar buscar” (voye chèche); "entrar” (antre) alguns dos que ficaram. ${ }^{16}$ Esses verbos

${ }^{15} \mathrm{O}$ termo fil tem a sua origem no verbo inglês fill, preencher, está associado ao processo burocrático de preencher os requisitos legais, chamado reunião familiar, como categoria estatal.

${ }^{16}$ Esses dois últimos procedimentos são geralmente realizados de forma indocumentada, sem burocracia estatal.

Horizontes Antropológicos, Porto Alegre, ano 21, n. 43, p. 51-78, jan./jun. 2015 
são utilizados e conjugados para descrever um “dever” (talvez o principal) de quem viaja. É comum a primeira pergunta feita a uma pessoa diaspora no Haiti: “quando vai 'mandar buscar' seu irmão?” (kilè w'ap voye chèche frè'w la?); “quando vai 'entrar' sua mãe?” (kilè w'ap antre manman'w?); “quando vai 'fil' para seus filhos?” (kilè w'ap fil pou pitit ou yo?). Os verbos fil, voye chèche e antre em créole podem ser utilizados tanto para as viagens por meio legal de uma solicitação de visto quanto para uma viagem clandestina financiada. É comum a pessoa diaspora receber críticas de alguém no Haiti por residir dez anos ou mais aletranje tendo filhos, irmãos ou pais no Haiti. Entrar, fil, mandar buscar algum membro da família constitui um valor moral da pessoa diaspora, é honrar a família diante dos vizinhos e dos familiares.

Diaspora é uma experiência familiar e de sociabilidade. As estruturas familiares na família extensa haitiana desempenham um papel importante na configuração da morfologia social da diaspora. Para aqueles numa situação indocumentada aletranje, a volta temporária pode tornar-se um desejo, um ideal imaginado, mas impossível de ser concretizado. Porém, isso deve ser nuançado, pois há aqueles que, apesar de não possuírem documentos aletranje, preferem voltar ao Haiti para sentir e ter orgulho de ser diaspora, mesmo arriscando não poder retornar aletranje. Dentre esses, os que permanecerem no Haiti deixarão de ser diaspora, do ponto de vista dos residentes no país. Mas, depois de um tempo, se voltarem a se reinstalar em outro lugar, quando retornarem temporariamente ao Haiti serão considerados novamente diaspora.

A esse processo chamo de rediasporização, referindo-me à pessoa que já tinha sido diaspora e volta a ser diaspora. Essa escala de análise permite romper com a dicotomia subjacente na ideia de retorno que implica uma relação de emigrante/imigrante, aqui/lá, mudando de paradigma e de abordagem, colocando o acento mais sobre a circulação e a mobilidade em si do que sobre a emigração e a imigração como se fossem polos antagônicos.

Do ponto de vista etnográfico, o termo diaspora tem um sentido articulado por três verbos: residir (viv) aletranje, voltar (tounen) ao Haiti e retornar (retounen) aletranje. Quem retorna definitivamente ao Haiti não é considerado diaspora e isso pode ser interpretado como o fracasso do seu processo de mobilidade. Essa epistemologia evoca ir-voltar-retornar, enfim, a mobilidade.

$\mathrm{O}$ fato de ser diaspora implica, principalmente do ponto de vista dos que ficam e das expectativas dos que saem, possuir dinheiro, ser uma pessoa bem-sucedida economicamente. Boa parte da economia do Haiti 
é mantida pelas remessas da diaspora. De acordo com os dados do Fundo Multilateral de Investimento (FOMIN) ligado ao Banco Interamericano de Desenvolvimento (BID), ${ }^{17}$ em 2006, o país recebeu US\$ 1.017.000.000 dos haitianos residentes nos Estados Unidos. Do Canadá, foram US\$ 230.000.000; da França, US\$ 130.000 .000 e da República Dominicana e das Bahamas, US\$ 33.000.000. Em 2007, as remessas enviadas para os familiares no Haiti superaram US\$ 1.065.000.000. Esse valor representa 24\% do Produto Interno Bruto (PIB) anual, embora as transferências legais observadas nesses dados não incluam envios informais. A diaspora haitiana possui um papel crucial na vida social e econômica do país.

Interessa destacar a implicação da diaspora no destino do Haiti, particularmente depois do sismo de 12 de janeiro de 2010. Logo após a tragédia de aproximadamente 230 mil mortos e milhares de feridos e desabrigados - de acordo com os dados oficiais - a notícia do ocorrido se espalhou pelo mundo. Boa parte dos familiares e compatriotas no exterior buscava comunicar-se para ter informações dos parentes, amigos e conhecidos. Em países como Estados Unidos, França, Canadá, entre outros, houve grande mobilização de haitianos, nas organizações não governamentais e associações haitianas (além das estatais e de outras nacionalidades) em prol dos milhares de vítimas do terremoto. As observações do antropólogo Omar Ribeiro Thomaz (2011), dias depois do tremor, lançam luz sobre essa questão.

Diante do colapso do sistema bancário e da Western Union, membros da diáspora se deslocaram ao Haiti com dinheiro no bolso. Na falta de voos para Porto Príncipe, as passagens dos EUA e do Canadá para Santo Domingo rapidamente se esgotaram, a fronteira terrestre dominicana-haitiana colapsou nos dois sentidos: no sentido daqueles que queriam abandonar o país e no dos que vinham de longe para trazer comida, remédios e dinheiro para parentes e amigos. (Thomaz, 2011, p. 277).

Além das contribuições em dinheiro, as pessoas diaspora contribuíram com medicamentos, materiais hospitalares e assistência técnica para ajudar as vítimas do terremoto. Alguns solicitaram férias de seus trabalhos aletranje,

${ }^{17}$ Cf. Inter-American Development Bank (2007). 
particularmente os profissionais na área da saúde, os médicos, enfermeiros, psicólogos, etc., para ir ao Haiti ajudar no atendimento aos feridos.

A partir do ano de 2012, o governo Martelly iniciou um programa que taxa as remessas enviadas da diaspora para o Haiti (1 dólar americano por remessa) e as ligações telefônicas internacionais recebidas (cinco centavos americanos a cada 30 minutos). Tais taxas, estipuladas em mais de US\$ 4 milhões por mês, visam financiar o Programa Escola Gratuita. Além de contribuir fortemente para a manutenção da estabilidade social e política, os haitianos da diaspora participam ativamente dos programas sociais do país.

A popularização da palavra na vida pública força a discutir o seu uso prático. Parte daqueles haitianos domiciliados nos Estados Unidos produzem músicas haitianas, chamadas músicas de diaspora. O estilo musical haitiano denominado konpa ou compas, possui os seus mais influentes grupos que dominam o cenário musical (trans)nacional haitiano sediados em Miami (Zenglen, T-Vice, Nu Look, Klass, Disip, Armonik) e em Nova York (Carimi, System Band, Phantom), apelidados de konpa diaspora. Esses grupos circulam nos territórios da diaspora haitiana nos diferentes países e no Haiti.

O mesmo acontece com o cinema: nos Estados Unidos existe a maior indústria de cinema haitiano, cinema diaspora. As roupas enviadas do exterior são denominadas pèpè ou rad diaspora (roupa diaspora). Quando funcionários da agência de câmbio CAM ou Western Union passam de casa em casa para entregar remessas em dólares, euros ou mercadorias, produtos alimentícios (arroz, feijão, azeite, etc.) enviados por residentes aletranje, os vizinhos costumam dizer que diaspora chega à casa ou entra na casa. Geralmente, parte deles ou mesmo o dinheiro são compartilhados com alguns vizinhos, conhecidos ou familiares. Em alguns rituais do vodu, é indispensável o uso da moeda americana, notas de um dólar ou centavos, denominadas lajan diaspora, moedas diaspora.

Há um ritual de preparação da viagem ao Haiti: compram-se vestidos, tênis, sapatos, perfumes, presentes, além de juntar dinheiro para levar ao país. A viagem da volta é planejada com bastante antecedência. Quando chegam, os mais endinheirados alugam um carro de última geração; exibem os vestidos de marca, os cordões de ouro; financiam festas para familiares, amigos e conhecidos, sendo geralmente chamados de gwo diaspora (grande diaspora).

É característica de sua linguagem, a pessoa diaspora incorporar, por exemplo, quando fala o créole, palavras em língua estrangeira. Os vindos dos Estados Unidos usam but, so, what; os da Guiana Francesa, mo, to, pronomes

Horizontes Antropológicos, Porto Alegre, ano 21, n. 43, p. 51-78, jan./jun. 2015 
do créole guianense; os da França, maison, monsieur. Os comportamentos, os valores morais do sucesso e a hierarquia social, características da pessoa diaspora no Haiti, criam, no imaginário dos que residem nesse país, viver no estrangeiro ser melhor do que lakay (literalmente a casa, mas aqui significando a terra natal). Mesmo entre aqueles com empregos no país, ocupando cargos no governo, nas agências internacionais, possuindo empresas particulares, ganhando salários entre US\$ 1.000 a US\$ 3.000 por mês - valores altos para os padrões haitianos - boa parte escolhe ir ao peyi etranje (país estrangeiro) para um dia ser diaspora. Assim, a mobilidade é cultivada como recurso para alcançar o progresso social, cultural e econômico do indivíduo.

\section{Viajar e partir}

Na base da concepção de diaspora discutida neste artigo, duas categorias descrevem e organizam os níveis de deslocamentos: pati (partir) e vwayaje (viajar). Esses dois verbos conjugam duas faces da mobilidade: aqueles que partem (pati) para peyi etranje e os que vão e voltam, aqueles que viajam (vwayaje). A ideia de pati envolve ir (talvez definitivamente) sem saber se voltará ou quando, está associada à busca de trabalho e à procura de uma vida econômica, chèche lavi miyò (tentando uma vida melhor). Geralmente, quando quem parte possui um visto de residência permanente, ele compra um bilhete somente de ida. Vwayaje, ao contrário, é viajar para permanecer temporariamente no peyi etranje, está associado ao turismo ou ao comércio. Quem viaja costuma comprar um bilhete de ida e volta.

Pati e vwayaje estão associadas à categoria prática de diaspora. Do ponto de vista dos que ficam, os viajantes são chamados, na expressão nativa, de diaspora lokal (diaspora local), porque ficam por pouco tempo aletranje. Possuem poder aquisitivo de classe média ou alta, que os permite viajar frequentemente. Geralmente possuem bens materiais no Haiti, negócios ou trabalham no país e passam alguns meses aletranje.

No caso daquele que parte, podendo ficar muitos anos aletranje, quando volta, depois desse tempo, é chamado de diaspora no Haiti, sem o sufixo diaspora lokal como aquele que viaja num vaivém. Dentre outras variações, quem parte e nunca volta não é chamado de diaspora, é considerado como alguém vivendo na diaspora, fora do Haiti. A decisão de não retornar, seja temporária ou definitiva, não significa romper os laços com o país ou com os familiares 
e os amigos, pois muitos desses lhes enviam dinheiro, mercadorias e objetos. Alguns são dirigentes de organizações e associações haitianas no lugar de instalação e influentes na vida política nacional à longa distância. Do ponto de vista deles, optam por nunca mais voltar pelas condições sociais precárias, pela falta de oportunidades de estudos e de emprego, pela instabilidade política e insegurança sanitária, socioeconômica e pública.

Diaspora é vista como uma categoria de interação. Ao mesmo tempo em que constrói as suas múltiplas identidades a partir de duas sociedades ou mais, ela não se desenraiza - no sentido próprio e forte do termo - do Haiti. Ela interconecta o universo haitiano com o de aletranje, realizando sínteses culturais fecundas constituídas entre os diferentes espaços de mobilidade internacional e o Haiti. A mobilidade faz parte da vida cotidiana da pessoa diaspora: ela constitui e vive permanentemente em novos espaços sociais e culturais.

Nem todas as pessoas diaspora, no contexto haitiano, estabelecem ou mantêm práticas transnacionais tais como formuladas pela abordagem do transnacionalismo. Assim, alguns autores procuram estabelecer a diferença entre diáspora e comunidade transnacional. De acordo com Michel Bruneau (2004, p. 153, tradução minha),

uma diáspora é oposta a um Estado-nação bem definido, bem delimitado, centralizado. É, ao contrário, um organismo extremamente decentralizado, policêntrico, mal definido sobre um mapa. Suas comunidades ou células de base são interligadas por fluxos de diversas naturezas com dois níveis superiores de organização: o nível nacional do país de acolhida e o nível mundial, internacional, coordenado ou não pelo país de origem, quando ele existe, ou por uma autoridade religiosa. Uma identidade comum se mantém, é a condição própria da existência de uma diáspora, mas ela adquire algumas especificidades em cada um dos países de acolhida no seio do sistema transnacional muito aberto que constitui a diáspora.

No mesmo texto, mais adiante, o referido autor segue a sua argumentação e afirma: “A comunidade transnacional se estrutura por uma ação política nos dois países. Ela faz circular as ideias, os comportamentos, as identidades e outros elementos do capital social. Ela constrói uma identidade própria.” (Bruneau, 2004, p. 178, tradução minha).

No universo dos haitianos, a socialização e a participação da pessoa diaspora aletranje não têm o mesmo sentido e forma do que as daquela no Haiti, 
porque ela está na dinâmica de reinterpretações culturais e sociais, devido ao fato de circular em várias referências e espaços de mobilidade em escalas supranacionais e não apenas numa comunidade em escala local. A pessoa diaspora aletranje é caracterizada pela multiplicidade das referências e dos valores culturais e sociais. Não basta saber circular, mas também saber agir e saber ser diaspora em diferentes contextos (trans)nacionais. Assim, ocupa espaços singulares no campo social e simbólico haitiano. Por isso, a sua experiência não pode ser pensada apenas no contexto de deslocamento, mas também como capital cultural no sentido bourdieusiano.

A pessoa diaspora possui diversos recursos culturais adquiridos em diferentes espaços de mobilidade e de pertencimento, o que lhe permite criar outros espaços de referência. Dessa forma, o termo diaspora, no universo haitiano, constitui um modo de ser, de vestir, de pensar e de agir, constituindo uma linguagem própria e estilo de vida. Nessa abordagem, há um conteúdo moral e cultural, mas a perspectiva da diáspora no sentido analítico como dispersão nos lugares e territórios não dá conta dele.

\section{0 termo diaspora, qualificando acõos e casas}

O termo diaspora também serve para qualificar ações. Geralmente no Haiti as pessoas falam w'ap fè bagay diaspora (está fazendo coisa de diaspora) por alguma atitude, comportamento, por comprar um carrão, um casarão, bancar uma festa grande. Ou se a pessoa está bem vestida com roupa nova e de marca, cordões de ouro, perfumada, as pessoas dizem ou sanble yon diaspora (você parece um diaspora). Nesse sentido, diaspora exprime um determinado tipo de comportamento. Para fazer coisa de diaspora, algumas mulheres grávidas no Haiti viajam aletranje, particularmente para os denominados grandes países (Estados Unidos, Canadá e França) com o intuito de dar à luz os seus filhos. Essa estratégia, além do status social e do valor moral da mulher, também garante aos filhos, e talvez aos pais, ter os documentos de residência do país no qual a criança nasce. Nessa acepção, é um valor social e moral; ao mesmo tempo, símbolo de um tipo de ascensão social.

Entretanto, por mais que diaspora seja uma afirmação positiva e um sonho de boa parte da população, o termo é basicamente ambivalente. Ele possui múltiplos sentidos, às vezes contraditórios. Interessa destacar que, no meu 
trabalho de campo, o termo diaspora aparece num registro mais positivo do que negativo, tanto do ponto de vista dos que ficam no Haiti quanto daqueles em mobilidade. Mas o termo pode ser também uma categoria de acusação, carregada de sentido pejorativo, quando aqueles que vão aletranje demonstram superioridade em relação aos enraizados no Haiti. E também, quando os que ficam sentem-se ameaçados, por "perder” lugares sociais e políticos para a pessoa diaspora no Haiti. Diaspora pran plas mwen (diaspora ocupa meu lugar), são expressões utilizadas para acusar a pessoa diaspora. Para os que ficam, ela é considerada incapaz de dirigir ou governar o país por ter vindo aletranje e desconhecer a realidade local.

Igualmente na sociedade, do ponto de vista das mulheres e dos homens notadamente, o termo diaspora pode servir de dispositivo de acusação, tensionando as relações matrimoniais, sobretudo quando os que ficam no Haiti separam-se dos seus maridos ou das esposas para relacionar-se com uma pessoa diaspora. Costumam dizer diaspora pran madanm mwen (diaspora pega minha mulher), diaspora vòlè mari' $m$ (diaspora rouba meu marido) ou fanm lan kite' $m$ poutèt yon diaspora (a mulher me deixou por causa de um diaspora).

Salienta-se que tais frases nativas sintetizam outros papéis atribuídos à pessoa diaspora. De acordo com alguns dos meus interlocutores no Haiti, essas tensões matrimoniais e relações de conflitualidade geralmente são motivadas pelo poder aquisitivo da pessoa diaspora ser superior ao daqueles que moram no Haiti, ou seja, o dinheiro que alguém do Haiti recebe num mês de uma pessoa diaspora, por exemplo, US\$ 400, pode ser equivalente ao salário de cinco meses de um companheiro residente no Haiti. ${ }^{18}$ Por isso, durante o trabalho de campo realizado no Haiti, algumas jovens me diziam que somente se relacionavam com diaspora. Do ponto de vista delas e também deles, estar com uma pessoa diaspora possibilita ter uma vida econômica melhor e, também, a possibilidade de um dia viajar ou partir aletranje, visto a pessoa diaspora poder fil e mandar buscar o companheiro que ficou no Haiti.

No entanto, há de ponderar-se que, no meu trabalho de campo, nem todas as mulheres pensavam namorar ou casar com diaspora para serem sustentadas economicamente, ou tampouco usar a sexualidade feminina como recurso

${ }^{18}$ Para aprofundar o debate sobre a questão de gênero no Haiti, ver os trabalhos de Braum, Dalmaso e Neiburg (2014). 
(Richman, 2003). É ambígua tal relação da diaspora. Não era incomum encontrar mulheres em Fonds-des-Nègres que não queriam relacionar-se com diaspora - por mais que fosse por amor e não por dinheiro - para não serem confundidas com aquelas que somente têm interesses econômicos, sobretudo para não serem confundidas ou chamadas de bouzen (prostituta).

Nesse sentido, construir uma casa no Haiti torna-se um objetivo essencial por muitos haitianos residentes no exterior. Ela é o lugar de encontro da e com a família. As atitudes da população haitiana em seus lares e as práticas cotidianas nesse espaço também devem ser compreendidas no contexto de redes transnacionais e diaspora, isto é, as redes de pessoas construtoras delas. A maioria de pessoas residentes no exterior que voltam ao Haiti para construir suas casas deixa parentes ou amigos nelas para cuidá-las, uma vez habitáveis. A abordagem etnográfica das casas mostra a relação entre a intensa circulação de haitianos no Haiti e fora dele, com suas casas nesse país, as redes de relações familiares, os laços afetivos, a "casa” e as "configurações de casas” (Marcelin, 1996, 1999) habitadas pelas famílias no contexto das redes dentro das quais elas interagem, bem como objetos e produtos do país estrangeiro.

Quando se examina a relação das casas (kay) e a diaspora, nelas não há apenas objetos da diaspora, elas são chamadas pelos haitianos (tanto os que ficam e os que partem) de kay diaspora (casas diaspora). Aquelas construídas no Haiti combinam objetos (eletrônicos e eletrodomésticos, etc.), materiais de construção (cerâmicas, portas, janelas, luzes, etc.) da diaspora com os do Haiti. ${ }^{19}$ Se diaspora é um valor moral e social, ter uma casa diaspora é um privilégio e torna-se um jeito de manter a qualidade da relação com os que ficam e, ao mesmo tempo, conectar-se com o local de origem.

\section{Peyi blan e diaspora}

Depois de apresentar as características e as dinâmicas da experiência da diaspora, estimo necessário problematizar as interações e os estereótipos articuladores das relações entre os haitianos no Haiti, no Brasil, no Suriname e na Guiana Francesa. A aproximação crítica do texto aqui apresentado com

19 Ver o quarto capítulo da minha tese de doutorado sobre "Casa diaspora, diaspora da casa” (Handerson, 2015). 
relação às narrativas que romantizam ou estigmatizam esses lugares se fundamenta na pesquisa etnográfica. Nesta parte do texto, mostrarei a relação indissociável entre peyi blan e diaspora.

Como os haitianos encaram a vida no Brasil, no Suriname e na Guiana Francesa? O que pensam desses lugares? Como os contrastam com a vida no Haiti ou em outros locais que eles imaginam como possíveis destinos, ou pelos quais já passaram ou onde têm familiares e amigos? Essas perguntas são cruciais para compreender o universo social dos sujeitos nesses espaços nacionais diversificados. Brezil pa peyi blan, Surinam pa peyi blan, Giyan pa peyi blan não são afirmações unânimes, pois nem todos os interlocutores pensavam dessa forma, mas eram recorrentes no universo pesquisado. Literalmente, a tradução seria a de eles não serem países "brancos". Aqui, blan não possui apenas uma conotação racializada, mas também de alteridade, de classe e de nação. Os usos e os sentidos da categoria blan relacionam a questão racial com a nacional e a de classe.

Peyi blan é uma categoria possuidora de várias significações e sentidos. Em alguns casos, pode ser entendida também como peyi etranje (país estrangeiro), peyi lòt bò dlo (país além do mar). São expressas e utilizadas entre os haitianos (aqueles residentes no Haiti e no exterior) para reportar-se aos países estrangeiros industrializados e desenvolvidos economicamente, na sua grande maioria compostos por uma população branca significativa, mas não necessariamente. Além disso, principalmente, nos quais podem ganhar em lajan diaspora, dólar americano e euro.

Para boa parte dos meus interlocutores haitianos no Brasil, Suriname e Guiana Francesa, ${ }^{20}$ nem todo peyi etranje é peyi blan: a República Dominicana, o Panamá, o Equador e o Peru são peyi etranje, mas não são considerados peyi blan, por acreditarem que, nesses países, não ganham em lajan diaspora, e não são “desenvolvidos” como Estados Unidos, Canadá, França, Inglaterra, etc. Ademais, peyi blan está associado aos produtos e objetos de qualidade, seja de alimentos ou de vestimentas, tudo o que é bom dizem ser do peyi blan. Essa associação possui sua origem nas importações dos produtos dos Estados

${ }^{20}$ Para saber como se operacionalizou a pesquisa, ter informações sobre quem são, de onde vieram e para onde vão os meus interlocutores, bem como a heterogeneidade entre eles, ver a minha tese de doutorado sobre Diaspora. As dinâmicas da mobilidade haitiana no Brasil, no Suriname e na Guiana Francesa (Handerson, 2015). 
Unidos e França para o Haiti. As pessoas diaspora costumam enviar produtos e objetos via contêiner para o país.

A imagem e a maneira pelas quais os interlocutores representavam o Brasil são paradoxais. Alguns afirmavam ser um peyi blan e outros, não. Os que diziam ser um peyi blan referiam-se ao fato de ser um país estrangeiro, ter uma das melhores economias mundiais, haver emprego. Os outros não referiam ser um peyi blan porque as pessoas não ganhavam em lajan diaspora. No Brasil, o salário mínimo era mínimo mesmo, comparado com o dos Estados Unidos, Canadá ou França. No Brasil seria mais difícil economizar.

Possuir algum membro da família aletranje é sinônimo de ter esperança de um dia "conhecer o país de Deus” (konnen peyi Bondye a), de pati ou vwayaje para peyi blan. A dimensão religiosa (de Deus) ganha toda sua força aqui para explicar o desejo de estar em mobilidade. O peyi blan seria um espaço simbólico imaginado, praticado e vivido. Nessa concepção, diaspora se nutre através de um sonho, uma utopia e também uma prática que se realiza pela mobilidade; de uma terra estrangeira imaginada, uma espécie de "lugar metafórico". Diaspora é, ao mesmo tempo, uma construção ideológica e prática que modela a vida social das pessoas. Diaspora e peyi blan não correspondem apenas a lugares geográficos, mas a um mundo idealizado e vivido.

No caso do Suriname, é um peyi etranje, não sendo considerado peyi blan, devido ao clima, ao salário que gira em torno de US\$200. No caso da Guiana Francesa, a maneira de ser representada é paradoxal. Às vezes, referiam-se à Guiana como se fosse um país, peyi Lagiyan (país Guiana), diziam não ser peyi blan pelo clima, por haver poucas opções de lazer e não possuir grandes prédios modernos. Era considerado um peyi nèg (país de negro) pela quantidade de negros e afirmavam ser uma reserva natural dos franceses no meio da Amazônia, mas no qual se pode economizar, porque se ganha em lajan diaspora, euros, entre 900 a 1.800 mensais. Quando se referiam à Guiana como departamento ultramarino da França, diziam ser um peyi blan, porque era dirigido pelo governo francês e por ganhar em euros.

O peyi etranje não considerado peyi blan é percebido como um lugar de passagem, um couloir, um corredor. São chamados de ti peyi (pequeno país, no sentido socioeconômico). Representam o início de um processo de mobilidade. É importante possuir o visto do ti peyi porque isso permite preencher as páginas do passaporte, demonstrando que faz vaivém e não pretende ficar no

Horizontes Antropológicos, Porto Alegre, ano 21, n. 43, p. 51-78, jan./jun. 2015 
exterior para depois solicitar um visto de um peyi blan como Estados Unidos, França ou Canadá, também chamados gran peyi ou gwo peyi (grande país).

A percepção de um país ser peyi blan ou não é diferente entre os que ficam e os que viajam. Nas cidades de Fonds-des-Nègres e Pemerle, os meus interlocutores usavam peyi blan como sinônimo de peyi etranje. Para estes, qualquer país estrangeiro é peyi blan, visto serem estranhos a "nós". Essa afirmação pode ser compreendida à luz desta frase: Blan pou nou, se tout sa ki diferan de nou, se lòt la, sa ki diferan an (Blan para nós é tudo o que é estranho a nós, é o outro, o diferente). Nesse sentido, mesmo um negro africano é considerado como blan por ser estrangeiro. O ser blan para estes não está (ou não está exclusivamente) associado à cor.

A palavra blan é utilizada também como sinônimo de ser estrangeiro, um não nacional, e também para referir-se àquele que vive bem economicamente, leva uma vida de conforto, possui casa grande, carro importado e uma boa renda. Blan está relacionada ao conforto, ao luxo. Por isso, entre os próprios haitianos, às vezes eles dizem ser fulano ou beltrano blan pelo comportamento, pela conduta, pela maneira de vestir, etc.

Se diaspora possui valor social e moral, ocupando lugares privilegiados na estruturação hierárquica de relações sociais no país, então, blan está no topo. Diaspora e blan servem de modelos paradigmáticos para a localização social. Assim, blan serve também para qualificar pessoas, dinheiro, mercadorias, ações, países e casas. O dinheiro enviado pela diaspora também é chamado de lajan blan (dinheiro blan). Quando se refere ao comportamento de "boa conduta”, ao agir humano, dizem se tankou blan mwen sèvi (é como blan que eu funciono) como categoria de autodesignação. As pessoas acostumadas a chegarem atrasadas aos lugares são qualificadas como aqueles que "não são como blan” (ou pa tankou blan). Estes não seriam exemplares por não agirem como blan. Os objetos como aparelhos domésticos, TV, roupas enviados para o país, também são chamadas de bagay blan (coisas de blan). As comidas são chamadas de manje blan. As casas construídas no Haiti por blan, pelas organizações não governamentais ou pelas agências internacionais são chamadas kay blan (casa blan). Como já vimos, boa parte dos países estrangeiros são também denominados peyi blan.

Blan é uma afirmação positiva, mas, ao mesmo tempo, deve ser nuançada pois ela pode servir também como termo de acusação. Pode estar relacionada a ser dominador e ser "colonial”. Há uma dimensão colonialista 
embutida na condição de existência de blan. Quando se usa a expressão w'ap sèvi tankou blan avè'm (está agindo como blan comigo), remete-se a uma relação de dominação e de subordinação. Em alguns contextos, quando blan está relacionado à presença dos marines - referindo-se aos militares - durante as diversas ocupações no país, incluindo a presença atual da Missão das Nações Unidas para a Estabilização no Haiti (MINUSTAH), a categoria blan tem um conteúdo de acusação de "imperialismo". Nesse último contexto, algumas expressões nativas ganham toda a sua força: blan pran peyi a (blan toma conta do país); blan pa vle peyi a mache (blan não deixa o país funcionar), e assim por diante.

Há uma relação estreita entre diaspora e peyi blan. Os haitianos chamados diaspora são aqueles que vão para os gwo peyi (grandes países), denominados de gwo diaspora (grande diaspora). Os residentes no Suriname, Equador, Chile, Cuba, incluindo Brasil, dependem do contexto. Os chamados ti peyi, quando voltam ao Haiti podem ser considerados ti diaspora (pequenos diaspora). Nesse sentido, o termo diaspora é um princípio organizacional.

Essas classificações são explicitadas no mundo social haitiano. O ponto aqui, contudo, é salientar e especificar quão estruturante e hierarquizante é o construto da relação entre gwo diaspora e ti diaspora, gwo peyi e ti peyi: quão profunda é a gramática e o campo semântico que as estruturam e apontam ainda para outro fato crucial: as dinâmicas da construção da hierarquia e da desigualdade no Haiti e as tensões que recaem sobre os haitianos que viajam para peyi blan ou não, dessa forma, reforçando a dimensão elitista da diaspora entre eles.

O ti peyi e a ti diaspora estão relacionados à expressão cunhada por Martínez (1995), “migrantes periféricos” ou "migração periférica”. O autor utilizou a expressão para descrever a experiência dos haitianos que vão à República Dominicana trabalhar nas indústrias de café e de cana-de-açúcar. A mobilidade dos haitianos para Estados Unidos, França e Canadá é diferente, porque circulam em universos de referência chamados de centros, os quais ocupam melhores posições da hierarquia econômica mundial.

Os haitianos valorizam essas classificações como critérios importantes de hierarquização para classificar países ou pessoas ocupantes de posições de prestígio ou não, entre os que viajam e os países estrangeiros. A categoria de atribuição ti diaspora geralmente é um estigma. Este termo ti diaspora não é aceito pelos haitianos com algum recurso econômico e de retorno 
de um chamado ti peyi. Estes também gostam de serem qualificados de diaspora, sem o prefixo ti (pequeno).

Bastava falar com os meus interlocutores no Haiti para observar o fato de que quem vem dos Estados Unidos, França, Canadá, considera-se superior e mais endinheirado do que os vindos da República Dominicana, Suriname, Cuba, Equador, Peru, Panamá, incluindo Brasil. Do ponto de vista dos que ficam, os primeiros países são mais prestigiosos do que os segundos. Os salários irrisórios daqueles que residem nesses últimos países não facilitam a mobilidade econômica e social deles no Haiti, em comparação com os ganhos daqueles que residem nos peyi blan. Entretanto, por mais que haja ambiguidade em relação à Guiana Francesa, se é considerada peyi blan ou não, os salários dos haitianos nesse departamento ultramarino, no entanto, são comparáveis com os da França e Estados Unidos, que permitem a eles acumular dinheiro para cumprir com as obrigações no Haiti, investir nesse país, comprando terreno ou construindo casas diaspora e financiar uma viagem para outro país.

Boa parte dos haitianos no Brasil, no Suriname e na Guiana Francesa também possuem familiares nos Estados Unidos, Canadá e na França. A imagem de sucesso social - real ou imaginado - nos peyi blan e o futuro promissor para o viajante e os familiares contribuem para que aqueles residentes nos "pequenos países" ou aqueles que tinham o projeto de ir a esses lugares mudassem de plano para irem aos países mais desenvolvidos.

Os residentes dos chamados "pequenos países” geralmente são incentivados por familiares e amigos, depois de habitarem, por algum tempo nos “pequenos países”, a irem aos Estados Unidos, França ou Canadá ou, pelo menos, conhecerem esses "grandes países". Aqueles que optam por permanecer nos "pequenos países" e eventualmente conseguem visitar os "grandes" por curtos períodos de tempo, nas férias, festas anuais ou simplesmente para rever os familiares e amigos, são chamados diaspora entènasyonal (diaspora internacional).

Diaspora internacional é aquela pessoa residente aletranje que circula entre diferentes locais da diaspora, caracterizando a multipolarização da mobilidade a partir da interpolaridade das relações familiares e de amizades. ${ }^{21}$

21 Peço emprestado de Emmanuel Ma Mung (1992, p. 187), as categorias “multipolaridade da migração”, caracterizando os diferentes polos dela e a "interpolaridade das relações”. 
A interpolaridade constituída pela diaspora internacional se traduz, ao mesmo tempo, pelas visitas de um polo migratório a outro e pela mobilidade nos diferentes espaços internacionais haitianos.

Diante disso, as experiências da diaspora multilocalizadas colocam diaspora internacional numa outra escala de interação, permitindo tecer laços familiares e revitalizar relações tanto com os que ficam quanto com os que partem. Se, no Haiti, a pessoa é designada grande diaspora por ter vindo de um peyi blan, diaspora internacional, ao chegar aos considerados grandes países, é classificada como diaspora da diaspora.

\section{Consideracões finais}

Ao tomar a pragmática da diaspora como objeto deste artigo, procurei examinar e mostrar como os sentidos da categoria estão relacionados ao universo da mobilidade e, ao mesmo tempo, evidenciei a maneira como a mobilidade se revela constitutiva do mundo social e dos horizontes de possibilidades dos haitianos. Com isso, não defendo um essencialismo, de todos eles, sem exceção, estarem em mobilidade nacional ou internacional, pois existem aqueles que ficam no Haiti por vários fatores. A mobilidade dos que partem contribui à imobilidade dos que ficam e vice-versa, particularmente quando aqueles em mobilidade enviam remessas para a manutenção dos que ficam ou quando quem fica financia a viagem dos que partem.

Neste artigo, em vez de utilizar o termo diaspora como categoria de análise para designar um grupo ou grupos de pessoas de nacionalidade e/ou ascendência haitiana residentes no exterior, o que, de alguma forma, esconde as diferenças entre essas pessoas, homogeneizando-as, porque nem todas elas se autoidentificam como diáspora nem possuem comprometimento com os projetos das diásporas, privilegiei a abordagem etnográfica da categoria, examinando empiricamente os modos pelos quais os haitianos a utilizam no seu cotidiano, tanto no Haiti como fora dele.

Foi possível observar, ao longo deste artigo, a existência de quatro níveis de diaspora expressadas na linguagem nativa: 1) diaspora lokal (diaspora local); 2) ti diaspora (pequena diaspora); 3) gwo diaspora (grande diaspora) e 4) diaspora entènasyonal (diaspora internacional). Diaspora internacional é, também, para usar as palavras de Bourdieu (1979), a expressão distintiva de 
uma posição privilegiada no espaço social, cujo valor superior determina-se objetivamente na relação com expressões engendradas a partir de condições diferentes.

Esses quatro níveis de análise etnográfico do termo diaspora não representam um modelo fechado, porém, abordam a dinâmica do mundo da diaspora, permitindo interrogar sobre os seus sentidos nativos. Assim, diaspora aparece como uma forma social, constituindo novas relações entre os sujeitos sociais, Estados nacionais, territórios geográficos e geografias sociais. Por isso, é preciso entender como o conceito de diaspora ressignifica a ideia de nacionalidade e transnacionalismo, engendrando aspectos de outros pertencimentos para além do território, mas dando sentido às redes solidárias, famílias ampliadas ou estendidas, redes afetivas, dentre outras.

\section{Referências}

ACHILLE, T. E. Les Haïtiens et la double nationalité. Montréal: Editions du Marais, 2007.

AUDEBERT, C. La diaspora haïtienne: territoires migratoires et réseaux transnationaux. Rennes: Presses Universitaires de Rennes, 2012.

BASCH, L.; GLICK-SCHILLER, N.; SZANTON-BLANC, C. Nations unbound: transnational projects, postcolonial predicaments, and deterritorialised nation-states. Basel: Gordon and Breach, 1994.

BORDES-BENAYOUN, C. La diaspora ou l'ethnique en mouvement. Revue Européenne des Migrations Internationales, Poitiers, v. 28, n. 1, p. 13-31, 2012.

BOURDIEU, P. La distinction: critique sociale du jugement. Paris: Éditions de Minuit, 1979.

BRAUM, P.; DALMASO, F.; NEIBURG, F. Gender issues: relations between men and women in the low-income districts of Port-au-Prince. Rio de Janeiro: Viva Rio: Nucec/UFRJ, 2014. Relatório de pesquisa. Disponível em: <http:// www.nucec.net/uploads/2/7/2/8/27281669/gender_rapport_ok.pdf $>$. Acesso em: 4 jun. 2014. 
BRUNEAU, M. Diasporas et espaces transnationaux. Paris: Anthropos, 2004.

CATHERINE, A.; TREYEN, P.-E. Population légale 2011: 237550 habitants en Guyane. Premiers Résultats, Cayenne, n. 100, janv. 2014. Disponível em: $<$ http://www.insee.fr/fr/insee_regions/guyane/themes/premiers_resultats/ Pop_legale2011_gy/pop_legale2011_gy.pdf>. Acesso em: 1 jul. 2014.

CLIFFORD, J. Diasporas. Cultural Anthropology, Washington, v. 9, n. 3, p. 302-338, 1994.

CLIFFORD, J. Routes: travel and translation in the late twentieth century. Cambridge: Harvard University Press, 1999.

COHEN, R. Global diasporas, an introduction. London: UCL Press, 1997.

CONGRÈS MONDIAL HAÏTIEN. Cahier nº 1. Montréal, 2005.

CONSOLIDATED recommendations. Documento do Haitian Diaspora Forum: Contributing to a Strategic Plan for Reconstruction and Development in Haiti, March 21-23, 2010. Washington: Organization of American States, 2010. Disponível em: <http://www.oas.org/en/ser/dia/ docs/RECOMMENDATIONS\%20-\%20HAITIAN\%20DIASPORA\%20 FORUM\%20-\%20Expanded.pdf>. Acesso em: 25 nov. 2013.

DUFOIX, S. Que sais-je?: les diasporas. Paris: Presses Universitaires de France, 2003.

DUFOIX, S. La dispersion: une histoire des usages du mot diaspora. Paris: Éditions Amsterdam, 2011.

GILROY, P. The Black Atlantic: modernity and double consciousness. London: Verso, 1993.

GLICK-SCHILLER, N. Long-distance nationalism. In: EMBER, M.; EMBER, C. R.; SKOGGARD, I. (Org.). Encyclopedia of diasporas. Boston: Springer, 2005. p. 570-580. 
GLICK-SCHILLER, N. Locality, globality and the popularization of a diasporic consciousness: learning from the Haitian case. In: JACKSON, R. O. Geographies of the Haitian diaspora. New York: Routledge, 2011. p. xxi-xxix.

GLICK-SCHILLER, N.; FOURON, G. Georges woke up laughing: longdistance nationalism and the search for home. Durham: Duke University Press, 2001.

GRANGER, S. Guyane et Surinam, à l'intersection des migrations caraïbes et sud-américaines. In: CALMONT, A.; AUDEBERT, C. (Dir.). Dynamiques migratoires de la Caraïbe. Paris: Karthala, 2007. p. 287-301. (Coll. Terres d'Amérique).

HANDERSON, J. Diaspora: as dinâmicas da mobilidade haitiana no Brasil, no Suriname e na Guiana Francesa. 2015. Tese (Doutorado em Antropologia Social)-Museu Nacional, Universidade Federal do Rio de Janeiro, Rio de Janeiro, 2015.

INTER-AMERICAN DEVELOPMENT BANK. Remittances to Haiti. 2007. Disponível em: <http://www.iadb.org/news/docs/HaitiSurvey.pps>. Acesso em: 6 mar. 2007.

MA MUNG, E. Dispositif économique et ressources spatiales: éléments d'une économie de diaspora. Revue Européenne des Migrations Internationales, Poitiers, v. 8, n. 3, p. 175-193, 1992.

MARCELIN, L. H. L'invention de la famille afro-americaine: famille, parenté et domesticité parmi les noirs du recôncavo da Bahia, Brésil. 1996. Tese (Doutorado em Antropologia Social)-Museu Nacional, Universidade Federal do Rio de Janeiro, Rio de Janeiro, 1996.

MARCELIN, L. H. A linguagem da casa entre os negros no recôncavo baiano. Mana, Rio de Janeiro, v. 5, n. 2, p. 31-60, 1999.

MARTÍNEZ, S. Peripheral migrants: Haitians and Dominican Republic sugar plantations. Knoxville: University of Tennessee Press, 1995. 
RICHMAN, K. Miami money and the home gal. Anthropology and Humanism, Arlington, v. 27, n. 2, p. 119-132, 2003.

SAFRAN, W. Diasporas in modern societies: myths of homeland and return. Diaspora, Toronto, v. 1, n. 1, p. 83-99, 1991.

SCHNAPPER, D. De l'État-nation au monde transnational. Du sens et de l'utilité du concept de diaspora. Revue Européenne de Migrations Internationales, Poitiers, v. 17, n. 2, p. 9-36, 2001.

THOMAZ, O. R. Eles são assim: racismo e o terremoto de 12 de janeiro de 2010 no Haiti. Cadernos de Campo, São Paulo, n. 20, p. 273-284, 2011.

Recebido em: 31/08/2014

Aprovado em: 03/03/2015 